\title{
Atividade fungitóxica de extratos vegetais e produtos comerciais contra Diplocarpon rosae
}

\author{
Janaina Miyashiro Simon, Kátia Regina Freitas Schwan-Estrada, Virlene do Amaral Jardinetti, Larisse Souza de \\ Campos Oliva, Jéssica Brasau da Silva, Ivan Gabriel Ruiz Scarabeli
}

Universidade Estadual de Maringá, Departamento de Agronomia, Avenida Colombo, $\mathrm{n}^{\circ}$ 5.790, Jardim Universitário, Zona 7. CEP 87020-900

Maringá, PR - Brasil.

Autor para correspondência: Janaina Miyashiro Simon (janainasimon@hotmail.com)

Data de chegada: 16/06/2016. Aceito para publicação em: 08/07/2016.

$10.1590 / 0100-5405 / 2209$

\section{RESUMO}

Simon; J.M.; Schwan-Estrada, K.R.F.; Jardinetti, V.A.; Oliva, L.S.C.; Silva, J.B.; Scarabeli, I.G.R. Atividade fungitóxica de extratos vegetais e produtos comerciais contra Diplocarpon rosae. Summa Phytopathologica, v.42, n.4, p.351-356, 2016.

O objetivo deste trabalho foi verificar o potencial de extratos oriundos de plantas medicinais (Rosmarinus officinalis L., Equisetum arvense L. $e$ Moringa oleifera Lam.) e produtos comerciais (a base de extratos vegetais, óleos vegetais e fosfito de potássio) no controle in vitro de Diplocarpon rosae. Avaliou-se o efeito dos tratamentos sobre o fitopatógeno pelo índice de velocidade de crescimento micelial, inibição do crescimento micelial, inibição da esporulação, índice de esporulação, síntese de proteínas, a atividade específica de peroxidase e catalase no micélio do fitopatógeno, utilizando extrato bruto aquoso (EBA) de folhas de R. officinalis (1\%); EBA de caules de $E$. arvense (1\%); EBA de sementes de $M$. oleifera $(1 \%)$; produto comercial a base de extratos vegetais fermentados $(0,01 \%)$; produto comercial a base de fosfito de potássio $(0,01 \%)$; produto comercial a base de óleos vegetais $(0,01 \%)$; produto a base de massa cítrica $(0,01 \%)$; fungicida a base de Tiofanato metílico (0,007\%); adjuvante $(0,0025 \%)$ BDA e BD. Pelos resultados observou-se maior redução do crescimento de $D$. rosae quando na presença do produto comercial a base de óleos vegetais. O EBA de $E$. arvense e o produto comercial a base de extratos vegetais fermentados apresentaram efeito anti-esporulante. Os tratamentos com EBA de R. officinalis, EBA de $E$. arvense, EBA de $M$. oleifera, produto comercial a base de óleos vegetais e produto a base de massa cítrica aumentaram a síntese de proteínas no micélio D.rosae. Houve aumento da atividade específica das enzimas peroxidase e catalase no micélio quando na presença do EBA de $R$. officinalis e produto comercial a base de fosfito de potássio, respectivamente. O EBA de $E$. arvense, e os produtos comerciais a base de óleos vegetais e a base de extratos vegetais fermentados, apresentaram resultados promissores no controle do fitopatógeno $D$. rosae.

Palavras-chave: controle alternativo, pinta preta, enzimas

\section{ABSTRACT}

Simon; J.M.; Schwan-Estrada, K.R.F.; Jardinetti, V.A.; Oliva, L.S.C.; Silva, J.B.; Scarabeli, I.G.R. Fungitoxic activity of plant extracts and commercial products against Diplocarpon rosae. Summa Phytopathologica, v.42, n.4, p.351-356, 2016.

The aim of this study was to verify the potential of extracts derived from medicinal plants (Rosmarinus officinalis L., Equisetum arvense L. and Moringa oleifera Lam.) and commercial products (based on plant extracts, plant oil and potassium phosphite) on the in vitro control of Diplocarpon rosae. The effect of treatments on the phytopathogen was evaluated according to the mycelial growth speed rate, mycelial growth inhibition, sporulation inhibition, sporulation rate, protein synthesis, and peroxidase and catalase specific activity on the mycelium of the phytopathogen, using aqueous crude extract (ACE) of $R$. officinalis leaves (1\%); ACE of E. arvense stems (1\%); ACE of M. oleifera seeds (1\%); commercial product based on fermented plant extracts $(0.01 \%)$; commercial product based on potassium phosphite $(0.01 \%)$; commercial product based on plant oil $(0.01 \%)$; product based on citrus mass $(0.01 \%)$; fungicide based on thiophanate methyl (0.007\%); and adjuvant $(0.0025 \%)$ in PDA and PD media. Results showed a higher reduction in the growth of $D$. rosae in the presence of commercial product based on plant oils. The ACE of E. arvense and the commercial product based on fermented plant extracts exhibited anti-sporulant effect. Treatments with ACE of $R$. officinalis, ACE of $E$. arvense, ACE of $M$. oleifera, commercial product based on plant oil and product based on citrus mass increased protein synthesis in $D$. rosae mycelium. There was increased specific activity of the enzymes peroxidase and catalase in the mycelium in the presence of ACE of $R$. officinalis and commercial product based on potassium phosphite, respectively. The ACE of $E$. arvense and the commercial products based on plant oils and fermented plant extracts showed promising results in the control of the phytopathogen $D$. rosae.

Keywords: alternative control, black spot, enzymes

A produção de flores no Paraná tem apresentado um crescimento significativo, o que tem se tornado uma nova atividade agrícola, principalmente na região Noroeste. Juntamente com este crescimento ocorre a necessidade do desenvolvimento de pesquisas, para suprir as necessidades dos produtores, principalmente em relação as doenças.

Algumas doenças acometem a cultura das roseiras e prejudicam a sua produção comprometendo a planta desde o desenvolvimento até a comercialização. Dentre as doenças que tem prejudicado a produção, podemos citar o ó́dio e a pinta preta. A pinta preta é uma doença fúngica causada pelo fitopatógeno Diplocarpon rosae Wolf que ocorre na parte aérea da planta e afeta o produto final. É caracterizada pela presença pontos pretos nas superfícies foliares, o que compromete a comercialização das rosas.

Uma alternativa para o controle desta doença, em substituição aos produtos químicos, é a aplicação de produtos à base de extratos de plantas medicinais, pois são capazes de produzir substâncias 
biologicamente ativas, que podem influenciar no metabolismo de um determinado organismo. Pesquisas desenvolvidas com extrato bruto ou óleo essencial, obtidos de plantas medicinais, têm indicado o potencial dos mesmos no controle de fitopatógenos, tanto por sua ação fungitóxica direta quanto por alterações fisiológicas na planta, como indução de enzimas relacionadas à patogênese e fitoalexinas, lignificação da folha, entre outras (20).

Dentre as plantas medicinais conhecidas que apresentam ação antimicrobiana está a Rosmarinus officinalis L., conhecida popularmente como alecrim apresenta, na composição do óleo essencial, princípios ativos como 1,8 cineol, $\alpha$-pineno, borneol e cânfora que tem atividade antimicrobiana conhecida $(11,17)$. Trabalhos in vitro com óleo essencial e extratos de $R$. officinalis sobre o crescimento de fitopatógenos vem sendo realizados por vários pesquisadores $(7,15,21)$.

Outra planta medicinal importante é a Equisetum arvense L., conhecida como cavalinha. Em sua composição encontra-se o ácido silícico, flavonóides, triglicerídeos, alcaloides, ácidos orgânicos, saponinas e taninos (23). O extrato desta planta tem sido utilizado no controle de doenças de morango e de flores $(2,5)$.

A planta Moringa oleifera Lam. conhecida como moringa, possui fontes de compostos fenólicos, $\beta$-caroteno, vitamina $C$ e proteínas totais e aminoácidos. Alguns autores já verificaram a fungitoxicidade desta planta no controle de Corynespora cassiicola e também na conservação de frutos $(6,18)$.

O uso extratos de vegetais em proteção de plantas quando comparado aos produtos sintéticos tem a vantagem de gerar novos compostos os quais os patógenos não se tornem capazes de inativar, além de serem menos tóxicos, serem degradados rapidamente pelo ambiente, possuírem um amplo modo de ação e de serem derivados de recursos renováveis (8).

Nesse contexto, objetivou-se estudar os efeitos de extratos oriundos de plantas medicinais, $R$. officinalis, E. arvense e M. oleifera e também alguns produtos comerciais naturais à base de extratos e óleos vegetais, como método alternativo de controle de $D$. rosae in vitro.

\section{MATERIAL E MÉTODOS}

O material vegetal utilizado no experimento constituiu-se de folhas de $R$. officinalis L., caules de $E$. arvense L. e sementes de $M$. oleifera Lam., colhidas durante o outono no período da manhã e em área experimental localizada no Município de Maringá-PR. Os extratos brutos aquosos (EBA) foram obtidos utilizando $10 \mathrm{~g}$ dos materiais vegetais, triturados em $100 \mathrm{~mL}$ de água destilada por $2 \mathrm{~min}$, em liquidificador e em seguida filtrados em gaze.

\section{Obtenção do isolado}

O fitopatógeno Diplocarpon rosae foi obtido a partir de folhas de roseiras com sintomas típicos da doença pinta preta, coletadas da área experimental da Faculdade Ingá. As placas contendo o fitopatógeno foram mantidas a $25 \pm 1{ }^{\circ} \mathrm{C}$ em estufa incubadora tipo B.O.D. (demanda bioquímica de oxigênio) durante 10 dias, e fotoperíodo de $12 \mathrm{~h}$. Após este período, discos de micélio do isolado foram transferidos para placas de Petri contendo meio BDA (batata-dextrose-ágar) e mantidas sob as mesmas condições até o momento de utilização nos respectivos ensaios.

\section{Fungitoxicidade in vitro}

Para o ensaio foram utilizados: EBA de folhas de R. officinalis (1\%); EBA de caules de $E$. arvense (1\%); EBA de sementes de $M$. oleifera $(1 \%)$; produto comercial a base de extratos vegetais fermentados
$(0,01 \%)+$ adjuvante (lecitina e ácido propiônico) $(0,0025 \%)$; produto comercial a base de fosfito de potássio $(0,01 \%)+$ adjuvante $(0,0025 \%)$; produto comercial a base de óleos vegetais $(0,01 \%)+$ adjuvante $(0,0025 \%)$; produto a base de massa cítrica $(0,01 \%)$; fungicida a base de Tiofanato metílico $(0,007 \%)$; adjuvante $(0,0025 \%)$ utilizado separadamente e somente meio BDA (controle).

Os tratamentos foram incorporados em meio BDA fundente $\mathrm{e}$ vertidos $20 \mathrm{~mL}$ em placas de Petri. Após a solidificação, discos de micélio ( $7 \mathrm{~mm}$ de diâmetro) do isolado fúngico foram depositados no centro das placas. Posteriormente mantidas em câmara de crescimento a $25 \pm 1{ }^{\circ} \mathrm{C}$ e fotoperíodo de $12 \mathrm{~h}$.

A partir do segundo dia após a repicagem, foram realizadas avaliações a cada 24 horas, até que o tratamento controle atingisse a borda da placa.

Com estas avaliações calculou-se o índice de velocidade de crescimento micelial (IVCM) e a inibição do crescimento micelial (ICM).

O cálculo do IVCM, expresso em $\mathrm{cm} \mathrm{dia}^{-1}$, foi realizado segundo proposto por Gomes (12). O crescimento micelial foi obtido pela medida do diâmetro das colônias em dois sentidos perpendiculares, com o auxílio de um escalímetro. Com os dados obtidos, foi determinada a área de crescimento micelial para cada tratamento, e realizado os cálculos de percentuais de inibição do crescimento micelial (ICM), utilizando a fórmula proposta por Bastos (1).

Trinta dias após a repicagem realizou-se a avaliação da esporulação fúngica, sendo que para isto, uma suspensão de conídios foi coletada pelo acréscimo de $10 \mathrm{~mL}$ de água destilada nas placas de Petri com o crescimento fúngico e, posteriormente, feita uma raspagem superficial do meio de cultura separando o micélio do meio de cultura para liberação dos esporos. A suspensão foi filtrada em gaze, com o auxílio de um funil de vidro e recolhida em um béquer. Desta solução foi coletado $1 \mathrm{~mL}$, acrescido de $200 \mu \mathrm{L}$ de Tween 20. Após agitação (10 segundos), procedeu-se a contagem do número de esporos em câmara de Neubauer, para posterior cálculo da porcentagem de inibição da esporulação.

Estudos sobre a quantificação de proteínas e atividade enzimática à $D$. rosae

Discos de micélio de $D$. rosae crescidos em meio BDA, foram repicados em erlenmeyers contendo $50 \mathrm{~mL}$ de meio líquido $\mathrm{BD}$, onde foram adicionadas os tratamentos: EBA de folhas de $R$. officinalis (1\%), EBA de caules de $E$. arvense (1\%), EBA de sementes de $M$. oleifera $(1 \%)$, produtos comercias a base de extratos vegetais fermentados, fosfito de potássio, extratos de óleos vegetais, na concentração de $0,01 \%$ acrescidos de $0,0025 \%$ de adjuvante (lecitina e ácido propiônico), produto a base de massa cítrica $(0,01 \%)$, fungicida a base de Tiofanato metílico $(0,007 \%)$, adjuvante utilizado separadamente $(0,0025 \%)$ e somente meio BD (controle).

O material foi mantido em câmara de germinação tipo B.O.D. a $25 \pm 1{ }^{\circ} \mathrm{C}$ com fotoperíodo de $12 \mathrm{~h}$, por 20 dias e agitado duas vezes ao dia. Posteriormente, o micélio foi filtrado em gaze lavado em água destilada por três vezes, pesado em balança analítica e transferido para solução de sacarose $0,2 \mathrm{M}(30 \mathrm{~mL})$ por $1 \mathrm{~h}$. O micélio foi retirado da solução e utilizado para a quantificação de proteínas solúveis totais e enzimas (peroxidase e catalase).

\section{Quantificação de proteínas}

Para a extração de proteínas, parte do micélio previamente pesado, foi macerado em nitrogênio líquido, adicionado tampão fosfato de potássio, $\mathrm{pH} 7,5$, a $100 \mathrm{mM}$ contendo $1 \mathrm{mM}$ de EDTA. O material obtido foi centrifugado a $4{ }^{\circ} \mathrm{C}$ durante $30 \mathrm{~min}$ a $15000 \mathrm{rpm}$ considerado 
o sobrenadante como extrato proteico. Para a quantificação de proteínas totais, uma alíquota de $2,5 \mathrm{~mL}$ do reagente de Bradford foi adicionada a $50 \mu \mathrm{L}$ de extrato enzimático, sob agitação e incubado por cinco minutos. Em seguida foi realizada a leitura em espectrofotômetro a $595 \mathrm{~nm}$. Como branco foi utilizado $50 \mu \mathrm{L}$ de água destilada com 2,5 $\mathrm{mL}$ de Bradford. A curva padrão foi determinada utilizando albumina de soro bovino. (3)

\section{Obtenção do extrato enzimático do micélio}

O extrato enzimático foi obtido de partes do micélio triturados em almofariz, utilizando nitrogênio líquido. Posteriormente foi feita a homogeneização em $4 \mathrm{~mL}$ de tampão fosfato de potássio 50 $\mathrm{mM}$ ( $\mathrm{pH} 7,0$ ) contendo $0,1 \mathrm{mM}$ de EDTA e adicionado $1 \%$ de polivinilpirrolidona (PVP). O extrato obtido foi centrifugado a $9000 \mathrm{rpm}$ durante trinta minutos a $4{ }^{\circ} \mathrm{C}$, sendo o sobrenadante considerado extrato enzimático e armazenado em freezer a $-20{ }^{\circ} \mathrm{C}$ para determinação do conteúdo de proteínas totais, atividade específica das enzimas peroxidase e catalase.

\section{Atividade específica das enzimas}

A atividade específica de peroxidase foi determinada pela medida da conversão do guaiacol em tetraguaiacol em $470 \mathrm{~nm}$ (16). A mistura de reação consistiu de $100 \mu \mathrm{L}$ do extrato enzimático do micélio de 2,9 $\mathrm{mL}$ de substrato (solução de 250 de guaiacol e $306 \mu \mathrm{L}$ de peróxido de hidrogênio em $100 \mathrm{~mL}$ de tampão fosfato $0,01 \mathrm{M}(\mathrm{pH} 6,0)$ ). Como padrão de referência, utilizou-se uma cubeta contendo $3 \mathrm{~mL}$ da solução de guaiacol e peróxido de hidrogênio em tampão fosfato. A atividade específica da peroxidase foi determinada por um período de 2 minutos. Os resultados foram expressos em unidades de absorbância min ${ }^{-1} \mathrm{mg}^{-1}$ de proteína.

A atividade específica de catalase foi obtida através do método de Tomankova et al. (22), pelo complexo estável formado pelo molibdato de amônio com peroxido de hidrogênio. Uma alíquota de $100 \mu \mathrm{L}$ do extrato enzimático (micélio) foi incubado em $500 \mu \mathrm{L}$ de mistura de reação contendo $60 \mathrm{mM}$ de peróxido de hidrogênio em tampão fosfato de potássio $60 \mathrm{mM} \mathrm{pH} \mathrm{7,4} \mathrm{a} 38^{\circ} \mathrm{C}$ por 4 minutos. Após esse período de incubação adicionou-se $500 \mu \mathrm{L}$ de molibdato de amônio $(32,4 \mathrm{mM})$. $\mathrm{O}$ consumo de peróxido de hidrogênio pela catalase foi determinado em espectrofotômetro na faixa do comprimento de onda de $405 \mathrm{~nm}$. O branco foi preparado para cada amostra através da adição de molibdato de amônio a mistura de reação, omitindo o período de incubação. A diferença entre a absorbância do branco e a amostra incubada indicou a quantidade de peroxido de hidrogênio utilizado pela enzima. A concentração de $\mathrm{H}_{2} \mathrm{O}_{2}$, foi determinada utilizando-se o coeficiente de

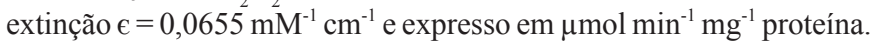

\section{Análise estatística}

O delineamento experimental foi inteiramente casualizado com 10 tratamentos e cinco repetições. Os dados foram submetidos a análise de variância (ANAVA), quando significativa, as médias foram comparadas pelo teste de Scott-Knott, com nível de significância de 5\%. As análises foram realizadas com o auxílio do programa estatístico SISVAR (9).

\section{RESULTADOS E DISCUSSÃO}

\section{Fungitoxicidade in vitro}

Os resultados referentes a fungitoxicidade in vitro para o índice de velocidade de crescimento micelial (IVCM), inibição do crescimento micelial (ICM), esporulação e inibição da esporulação, estão representado na Tabela 1.

Os tratamentos que promoveram maior controle in vitro do fitopatógeno $D$. rosae em relação ao IVCM e ICM quando comparado a testemunha, foi o Tiofanato metílico (T8), seguido do produto comercial a base de óleos vegetais (T6), EBA de $R$. officinalis (T1), produto comercial a base de fosfito de potássio (T5) e produto a base de massa cítrica (T7), reduzindo em $100 \%, 56 \%, 34 \%, 34 \%$, e $28 \%$ o crescimento micelial, respectivamente, estes resultados demonstraram o efeito fungistático dos produtos naturais testados.

Observou-se que os tratamentos com produto comercial a base de extratos vegetais fermentados, adjuvante e EBA de $E$. arvense também diferiram estatisticamente da testemunha, reduzindo parcialmente em $22 \%, 19 \%$ e $11 \%$ o crescimento do patógeno e apenas o EBA de $M$. oleifera, não diferiu.

Insenberg e Nozaki (13) obtiveram resultados semelhantes in vitro contra $D$. rosae com diferentes concentrações de óleo essencial de alfavaca (Ocimum basilicum), verificando que o óleo inibiu o crescimento micelial do fungo nas concentrações acima de $10 \mu \mathrm{L}$. Itako et al. (14) também verificaram a redução de $49,06 \%$ do crescimento micelial de Cladosporium fulvum em relação a testemunha utilizando extrato aquoso de alecrim na concentração de $40 \%$. Caixeta et. al. (4) estudando os efeitos do fosfito de potássio sobre fungos patogênicos do feijoeiro, verificaram a ação inibitória do fosfito de potássio nas doses de 0,$125 ; 0,25$ e $0,5 \mu \mathrm{L} \mathrm{mL}^{-1}$ sobre o crescimento micelial de Colletotrichum lindemuthianum.

Os esporos são unidades reprodutivas e infectivas dos fungos fitopatogênicos responsáveis por produzir propágulos que se disseminam e infectam a planta. Assim, quanto maior a inibição da formação de esporos, mais eficiente é o produto. Na Tabela 1 observa-se que os tratamentos com EBA de Equisetum arvense (T2) e produto comercial a base de extratos vegetais fermentados (T4), inibiram a esporulação do fitopatógeno $D$. rosae constatando efeito

Tabela 1. Índice de velocidade de crescimento micelial (IVCM), inibição do crescimento micelial (ICM), esporulação e inibição da esporulação do fungo Diplocarpon rosae submetidos aos diferentes tratamentos

\begin{tabular}{ccccc}
\hline Tratamento & $\begin{array}{c}\text { IVCM } \\
\left(\mathrm{cm} \mathrm{dia}^{-1}\right)\end{array}$ & $\begin{array}{c}\text { ICM } \\
(\%)\end{array}$ & $\begin{array}{c}\text { Esporulação } \\
\left(\times 10^{4}\right)\end{array}$ & $\begin{array}{c}\text { Inibição da } \\
\text { esporulação (\%) }\end{array}$ \\
\hline T1 & $0,73 \mathrm{c}$ & $34,52 \mathrm{c}$ & $1,00 \mathrm{~d}$ & $5,00 \mathrm{c}$ \\
T2 & $0,88 \mathrm{e}$ & $11,41 \mathrm{f}$ & $0,15 \mathrm{a}$ & $81,66 \mathrm{a}$ \\
T3 & $0,95 \mathrm{f}$ & $0,00 \mathrm{~g}$ & $0,80 \mathrm{~d}$ & $11,66 \mathrm{c}$ \\
T4 & $0,81 \mathrm{~d}$ & $22,72 \mathrm{e}$ & $0,20 \mathrm{a}$ & $75,00 \mathrm{a}$ \\
T5 & $0,75 \mathrm{c}$ & $34,08 \mathrm{c}$ & $0,40 \mathrm{~b}$ & $49,99 \mathrm{~b}$ \\
T6 & $0,60 \mathrm{~b}$ & $56,54 \mathrm{~b}$ & $0,40 \mathrm{~b}$ & $53,33 \mathrm{~b}$ \\
T7 & $0,78 \mathrm{c}$ & $28,26 \mathrm{~d}$ & $0,55 \mathrm{c}$ & $35,00 \mathrm{c}$ \\
T8 & $0,00 \mathrm{a}$ & $100,00 \mathrm{a}$ & $0,00 \mathrm{a}$ & $100,00 \mathrm{a}$ \\
T9 & $0,82 \mathrm{~d}$ & $19,51 \mathrm{e}$ & $0,75 \mathrm{~d}$ & $15,00 \mathrm{c}$ \\
T10 & $0,94 \mathrm{f}$ & $0,00 \mathrm{~g}$ & $0,85 \mathrm{~d}$ & $0,00 \mathrm{c}$ \\
\hline CV (\%) & 4,64 & 13,21 & 36,43 & 44,34 \\
\hline
\end{tabular}

Tratamentos: T1: EBA(1\%) Rosmarinus officinalis, T2: EBA(1\%) de Equisetum arvense, T3: EBA (1\%) de Moringa oleifera, T4: Produto comercial a base de extratos vegetais fermentados $(0,01 \%)$, T5: Produto comercial a base de fosfito de potássio $(0,01 \%)$, T6: Produto comercial a base de óleos vegetais $(0,01 \%)$, T7: produto a base de massa cítrica $(0,01 \%)$, T8: Tiofanato metílico $(0,007 \%)$, T9: Adjuvante $(0,0025 \%)$, T10: BDA. Médias seguidas da mesma letra na coluna não diferem entre si pelo Teste Scott-Knott $(\mathrm{P}<0,005)$. 
anti-esporulante.

Os tratamentos com produto comercial a base de fosfito de potássio (T5) e produto comercial a base de óleos vegetais (T6) também reduziram significativamente a esporulação de $D$. rosae em relação a testemunha (T10), inibindo $49 \%$ e $53 \%$ a esporulação. Da mesma forma alguns trabalhos utilizando fosfito e óleos vegetais mostraram resultados promissores no controle de fungos. Caixeta et al. (4) verificaram ainda que o fosfito de potássio nas doses $0,125 \mu \mathrm{L} \mathrm{mL}{ }^{-1}$, $0,25 \mu \mathrm{L} \mathrm{mL}^{-1}$ e $0,5 \mu \mathrm{L} \mathrm{mL}^{-1}$ reduziram significativamente a esporulação do fungo Fusarium oxysporum f.sp. phaseoli. Insenberg e Nozaki (13) também verificaram que o óleo essencial de Ocimum basilicum inibiu parcialmente a produção de esporos nas concentrações de $2,5 \mu \mathrm{L}$ e $5 \mu \mathrm{L}$. Os tratamentos com EBA de $R$. officinalis (T1), EBA de M. oleifera (T3) e adjuvante (T9) não diferiram estatisticamente da testemunha (T10).

Com relação a inibição da esporulação de $D$. rosae, os tratamentos utilizados apresentaram inibição acima de de $75 \%$ de inibição como o fungicida Tiofanato metílico, o EBA de E. arvense e o produto comercial a base de extratos vegetais fermentados) e outros que inibiram em até $53 \%$ (fosfito de potássio e produto comercial a base de óleos vegetais).

Estudos sobre a síntese de proteínas e atividade enzimática à D. rosae

\section{Síntese de proteína}

$\mathrm{O}$ efeito dos tratamentos sobre a síntese de proteínas no micélio de D. rosae está representado na Figura 1, onde se pode observar o aumento na concentração de proteínas totais no micélio de $D$. rosae em comparação a testemunha nos tratamentos com EBA de $R$. officinalis (T1), EBA de E. arvense (T2), EBA de $M$. oleifera (T3), produto comercial a base de óleos vegetais (T6) e produto a base de massa cítrica (T7), com 0,$4 ; 0,8 ; 0,6 ; 0,4$ e 0,6 vezes mais proteínas totais do que a testemunha $(\mathrm{BD}-\mathrm{T} 10)$.

Supõem-se que o fitopatógeno possa ter utilizado o meio com os
EBAs e o óleo vegetal, como fonte de nutrientes, o que pode ter causado o aumento de proteínas totais. Roma (19) estudando o mecanismo de ação do fosfito de potássio a Rhizopus stolonifer, verificou incremento na síntese de proteína em concentrações crescentes do produto $(5 \mathrm{e}$ $\left.10 \mathrm{~mL} \mathrm{~L}^{-1}\right)$.

Efeito sobre a indução de peroxidase de guaiacol e catalase

Em relação a atividade de peroxidase de guaiacol em micélio de $D$. rosae, representada na Figura 2, pode-se observar o aumento da enzima peroxidase apenas no tratamento com EBA de $R$. officinalis (T1) sendo 0,64 vezes maior que a testemunha. O tratamento Tiofanato metílico (T8) não apresentou atividade em relação a enzima peroxidase, pois não houve crescimento do micélio. Os demais tratamentos não diferiram da testemunha BD (T10).

Os fungos produzem enzimas que hidrolisam o substrato tornando-o assimilável, possivelmente o EBA de $R$. officinalis esteja agindo como fonte de carbono e energia levando ao maior crescimento micelial de D. rosae.

Em relação a atividade específica da enzima catalase em micélio de D. rosae (Figura3), pode-se observar que o tratamento com produto comercial a base de fosfito de potássio (T5) obteve atividade da enzima 1,38 vezes maior que a testemunha.

As enzimas antioxidativas são importantes na proteção contra as espécies ativas de oxigênio (EAOs) geradas durante o metabolismo celular normal. Esse processo de detoxificação é importante para que os fitopatógenos possam agir contra os oxidantes liberados pela planta como resposta primaria de defesa.

A presença dos extratos vegetais gerou uma condição de estresse, o que pode ter levado a danos na membrana plasmática, resultando na formação de espécies ativas de oxigênio (EAOs). Essas EAOs consequentemente podem ter induzido o fungo a produzir ou incrementar a atividade de peroxidase e catalase para detoxificação.

Fialho et al. (10) estudaram a resposta antioxidativa do fungo

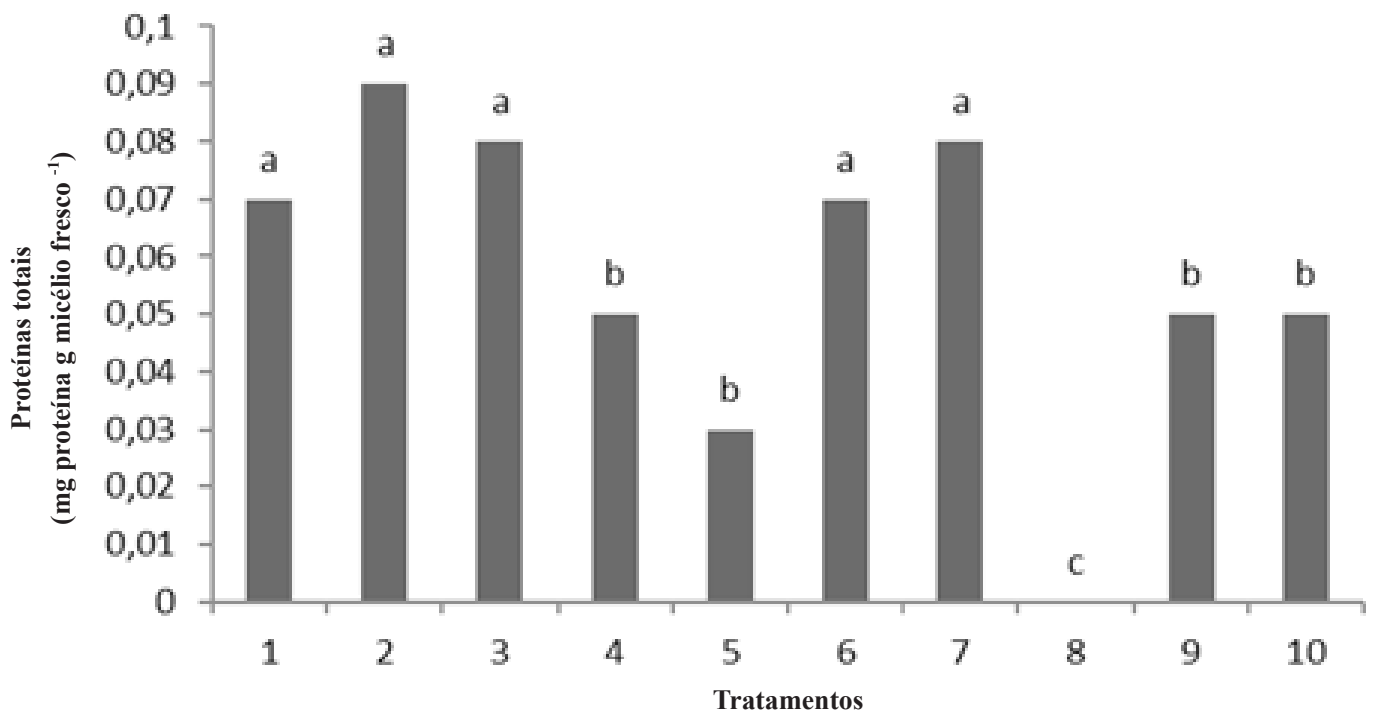

Figura 1. Efeito dos tratamentos sobre a síntese de proteínas no micélio de Diplocarponrosae cultivado em meio líquido batata-dextrose (BD), após 20 dias.

Tratamentos: T1: EBA (1\%) Rosmarinus officinalis, T2: EBA (1\%) de Equisetum arvense, T3: EBA (1\%) de Moringa oleifera, T4: Produto comercial a base de extratos vegetais fermentados $(0,01 \%)$, T5: Produto comercial a base de fosfito de potássio $(0,01 \%)$, T6: Produto comercial a base de óleos vegetais $(0,01 \%)$, T7: produto a base de massa cítrica $(0,01 \%)$, T8: Tiofanato metílico (0,007\%), T9: Adjuvante ( $0,0025 \%)$, T10: BD. Médias seguidas da mesma letra não diferem entre si pelo Teste Scott-Knott $(\mathrm{P}<0,005)$. Cv $(\%): 37,38$. 


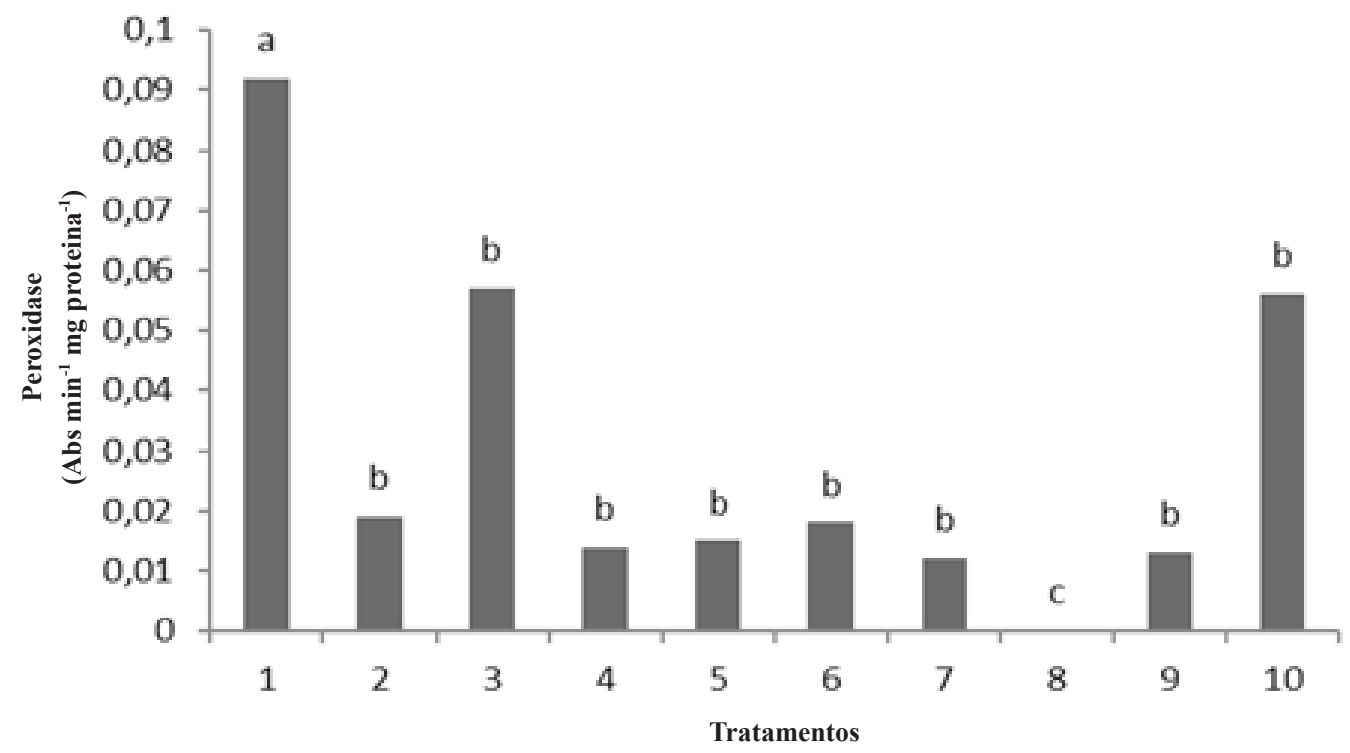

Figura 2. Atividade específica de peroxidase em micélio de Diplocarpon rosae, cultivado em meio BD contendo diferentes tratamentos, após 20 dias.

Tratamentos: T1: EBA (1\%) Rosmarinus officinalis, T2: EBA (1\%) de Equisetum arvense, T3: EBA (1\%) de Moringa oleifera, T4: Produto comercial a base de extratos vegetais fermentados $(0,01 \%)$, T5: Produto comercial a base de fosfito de potássio $(0,01 \%)$, T6: Produto comercial a base de óleos vegetais $(0,01 \%)$, T7: produto a base de massa cítrica $(0,01 \%)$, T8: Tiofanato metílico $(0,007 \%)$, T9: Adjuvante $(0,0025 \%)$, T10: BD. Médias seguidas da mesma letra não diferem entre si pelo Teste Scott-Knott $(\mathrm{P}<0,005)$. Cv (\%):80,3.

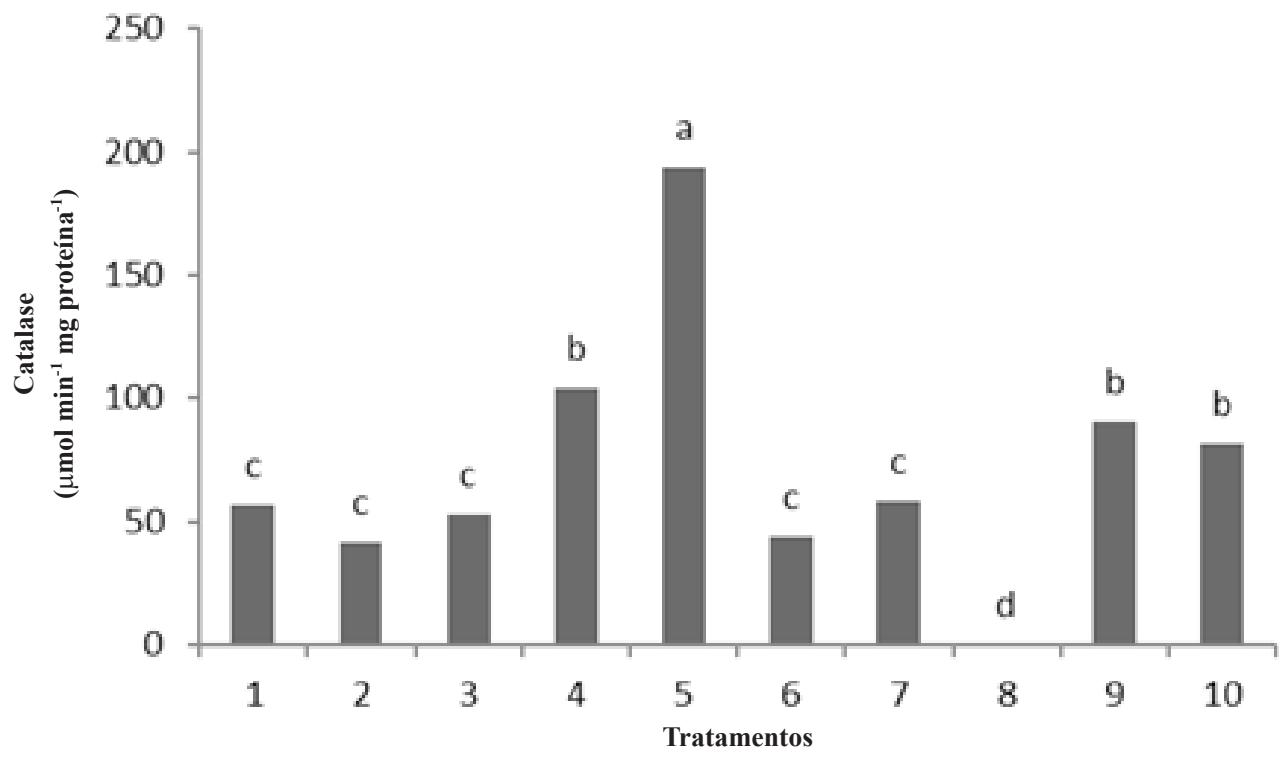

Figura 3. Atividade específica de catalase em micélio de Diplocarpon rosae, cultivado em meio BD contendo diferentes tratamentos, após 20 dias.

Tratamentos: T1: EBA (1\%) Rosmarinus officinalis, T2: EBA (1\%) de Equisetum arvense, T3: EBA (1\%) de Moringa oleifera, T4: Produto comercial a base de extratos vegetais fermentados $(0,01 \%)$, T5: Produto comercial a base de fosfito de potássio $(0,01 \%)$, T6: Produto comercial a base de óleos vegetais $(0,01 \%)$, T7: produto a base de massa cítrica $(0,01 \%)$, T8: Tiofanato metílico (0,007\%), T9: Adjuvante (0,0025\%), T10: BD. Médias seguidas da mesma letra não diferem entre si pelo Teste Scott-Knott $(\mathrm{P}<0,005)$. Cv $(\%): 48,3$.

causador da pinta preta em citrus (Guignardia citricarpa) através de compostos voláteis produzidos por Saccharomyces cerevisae e observaram aumento na atividade das enzimas antioxidantes superóxido dismutase e catalase nas primeiras 24 a $48 \mathrm{~h}$ de exposição aos compostos voláteis orgânicos, causando estresse oxidativo nos microorganismos.

Com base nos resultados obtidos observou-se que os mesmos atuam de maneira distinta sobre o fitopatógeno. O produto comercial a base de óleos vegetais apresentou maior efeito fungistático de $D$. rosae; o EBA de E. arvense e o produto comercial a base de extratos vegetais fermentados apresentaram efeito anti-esporulante; os EBAs de $R$. officinalis, E. arvense, M. oleifera e produto comercial a base de óleos vegetais aumentaram a síntese de proteína no micélio e o EBA 
de $R$. officinalis e produto comercial a base de fosfito de potássio aumentaram a atividade específica de peroxidase e catalase no micélio, respectivamente.

Assim, estes produtos naturais apresentam resultados promissores no controle do fitopatógeno $D$. rosae.

\section{AGRADECIMENTOS}

Ao CNPq - Conselho Nacional de Desenvolvimento Científico e Tecnológico, pela concessão da bolsa à primeira e segunda autora.

\section{REFERÊNCIAS}

1. Bastos, C.N. Efeito do óleo de Piper aduncum sobre Crinipelis e outros fungos fitopatogênicos. Fitopatologia Brasileira, Brasília, v.22, n.3, p.441-3, 1997.

2. Bertalot, M.J.A.; Carvalho-Pupatto, J.G.; Furtado, E.L.; Mendoza, E.; Mendes, R.D.; Buso, D.R. Controle alternativo de Mycosphaerella fragariae na cultura de morango orgânico. Revista brasileira de Agorecologia, Porto Alegre, v.7.n.2, p.170-177, 2012.

3. Bradford, M.M. A rapid and sensitive method for the quantification of microgram quantities of protein utilizing the principle of protein-dye binding. Analytical Biochemistry, Amsterdam, v. 72, p. 248-254, 1976.

4. Caixeta, A.O.; Vieira, B.S.; Canedo, E.J. Efeito do fosfito de potássio sobre fungos fitopatogênicos do feijoeiro. Revista do Centro Universitário de Patos de Minas, Patos de Minas, v. 2178, p.7662, 2012.

5. Camatti-Sartori, V.; Magrini, F.E.; Crippa, L.B.; Marchett, C.; Venturin, L.; Silva-Ribeiro, R.T.; Avaliação in vitro de extratos vegetais para o controle de fungos patogênicos de flores. Revista Brasileira de Agroecologia, Porto Alegre, v.6, n.2, p.117- 122, 2011.

6. Cruz, M.E.S; Cruz, M.J.S; Nanami, D.S.Y, Schwan-Estrada, K.R.F; Simon, J.M.; Ryche, A.G.G. Moringa oleifera na conservação de banana em póscolheita. In: Silva, G. F.; Bergamasco, R.; Serafini, M. R.; Sant`Anna, M. C. S. Potencialidades da Moringa oleifera Lam. São Cristovão: Editora UFS 2013. v. 3, cap. 30, p. 345-358.

7. Díaz Dellavalle, P.; Cabrera, A.; Alem, D.; Larrañaga, P.; Erreira, F.; Rizza, M.D. Antifungal activity of medicinal plant extracts against phytopathogenic fungus Alternaria spp. Chilean Journal of Agricultural Research, Canelones, v.71, p.231-239, 2011.

8. Ferraz, S.; Lopes, E.A.; Amora, D.X. Controle de fitonematoides com o uso de extratos e óleos essenciais de plantas. In: Poltronieri, L. S.; Ishida, A. K. N. (Ed). Métodos alternativos de controle de insetos-praga, doenças e plantas daninhas. Panorama atual e perspectivas na agricultura. Belém: EMBRAPA Amazônia Oriental 2008. p.153-186.

9. Ferreira, D.F. Sisvar: a computer statistical analysis system. Ciência e Agrotecnologia, Lavras, v.35, p.1039-1042, 2011.

10. Fialho, M.B.; Carvalho, G.; Martins, P.F.; Azevedo,R.A.; Pascholati, S.E.F. Antioxidative response of the fungal plant pathogen Guignardia citricarpa to antimicrobial volatile organic compounds. African Journal of Microbiology Research, África, v. 8, n. 20, p. 2077-2084, 2014.

11. Gachkar, L.; Yadegari, D.; Rezaei, M.B.; Taghizadeh, M.; Astaneh, S.A.; Rasooli, I. Chemical and biological characteristics of Cuminum cyminum and Rosmarinus officinalis essential oils. Food Chemistry, Tehran, v.102, p.898 904, 2007.

12. Gomes, A.S. Purificação, caracterização físico-quimica e biológica de proteínas ligantes à quitina presentes nas sementes de Moringa oleifera Lamarck. 2002. 100f. Monografia de graduação em Ciência biológicas, Departamento de Biologia, Universidade Federal do Ceará, Fortaleza.

13. Isenberg, M. \& Nozaki, M.H. Controle alternativo de Diplocarpon rosae. Revista Varia Scientia Agrárias, Toledo, v.3, n.2, p.135-145, 2013.

14. Itako, A.T.; Schwan-Estrada, K.R.F.; Stangarlin,J.R.; Tolentino Júnior, J.B; Cruz, M.E.S. Controle de Cladosporium fulvum em tomateiro por extratos de plantas medicinais. Arquivos do Instituto Biológico, Maringá, v.76, n.1, p.75-83, 2009.

15. Itako, A.T.; Schwan-Estrada, K.R.F.; Tolentino Júnior, J.B.; Stangarlin, J.R.; Cruz, M.E.S. Atividade antifúngica e proteção do tomateiro por extratos de plantas medicinais. Tropical Plant Pathology, Brasília, v.33, n.3, p.241-244, 2008

16. Lusso, M.F.G. \& Pascholati, S.F. Activity and isoenzymatic pattern of soluble peroxidases in maize tissues after mechanical injury or fungal inoculation. Summa Phytopathologica, Botucatu, v.25, p.244-249, 1999.

17. Maia, A.J.; Schwan-Estrada, K.R.F.; Faria, C.M.D.R.; Oliveira, J.S.B.; Jardinetti, V.A.; Batista, B.N. Óleo essencial de alecrim no controle de doenças e na indução de resistência em videira. Pesquisa Agropecuária Brasileira, Brasília, v.49, n.5, p.330-339, 2014.

18. Rodrigues, M.S.; Jardinetti, V.A.; Schwan-Estrada, K.R.F; Cruz, M.E.S. Uso de Moringa oleifera Lam. no controle de Corynespora casiicola em tomateiro. In: Silva, G. F.; Bergamasco, R.; Serafini, M. R.; Sant`Anna, M. C. S. Potencialidades da Moringa oleifera Lam. São Cristovão: Editora UFS 2013. v. 3, cap. 33, p. 385-394.

19. Roma, R.C.C. Fosfito de potássio no controle de doenças pós-colheita em bagas de uva Itália e possíveis mecanismos de ação à Rhizopus stolonifer. 2013. 117p. Tese (Doutorado em Ciências). Escola Superior de Agricultura "Luiz de Queiroz", Universidade de São Paulo, Piracicaba.

20. Schwan-Estrada, K.R.F. \& Stangarlin J.R. Extratos e óleos essenciais de plantas medicinais na indução de resistência. In: Cavalcanti L.S.; Di Piero R.M.; Cia, P.; Pascholati, S.F.; Resende, M.L.V.; Romeiro, R.S. (Eds.) Indução de resistência em plantas a patógenos e insetos. Piracicaba: FEALQ, 2005. p.125-132.

21. Soylu, E.M.; Soylu, S.; Kurt, S. Antimicrobial activities of the essential oils of various plants against tomato late blight disease agent Phytophthora infestans. Mycopathologia. Hatay, v.161, p.119-128, 2006.

22. Tomanková K.; Luhová, L.; Petrivalský, M.; Pec, P.; Lebeda, A. Biochemical aspects of reactive oxygen species formation in the interaction between $L y$ copersicon spp. and Oidium neolycopersici. Physiological and Molecular Plant Pathology, London, v.68, p.22-32, 2006.

23. Vaz, A.P.A. \& Jorge, M.H.A. Série Plantas Medicinais Condimentares e Aromáticas. Cavalinha. Corumbá-MS: Embrapa Pantanal, 2006. 